\title{
Hamiltonian Laceability in Line Graphs
}

\author{
Manjunath.G \\ Gopalan College of \\ Engineering \& Mgmt.Bangalore
}

\author{
Murali.R \\ Dr.Ambedkar Institute of \\ Technology, \\ Bangalore
}

\author{
Girisha.A \\ Acharya Institute of \\ Technology, \\ Bangalore
}

\begin{abstract}
A Connected graph $\mathrm{G}$ is a Hamiltonian laceable if there exists in $\mathrm{G}$ a Hamiltonian path between every pair of vertices in $\mathrm{G}$ at an odd distance. $\mathrm{G}$ is a Hamiltonian-t-Laceable (Hamiltonian$t^{*}$-Laceable) if there exists in $\mathrm{G}$ a Hamiltonian path between every pair (at least one pair) of vertices at distance ' $t$ ' in G. $1 \leq$ $\mathrm{t} \leq$ diamG. In this paper we explore the Hamiltonian- $\mathrm{t}^{*}$ laceability number $\left(\lambda *{ }_{(t)}\right)$ of graph L (G) i.e., Line Graph of $\mathrm{G}$ and also explore Hamiltonian-t*-Laceable of Line Graphs of Sunlet graph, Helm graph and Gear graph for $\mathrm{t}=1,2$ and 3 .
\end{abstract}

\section{Keywords}

Connected graph, Line graph, Sun let graph, Helm graph, Wheel graph, Gear graph and Hamiltonian-t-laceable graph.

\section{INTRODUCTION}

All graphs considered here are finite, simple, connected and undirected graph. Let $(G=V(G), E(G))$ be a graph. $|V(G)|$ and $|E(G)|$ are called the order and the size of $\mathrm{G}$ respectively. The order of $\mathrm{G}$ denoted by $\mathrm{O}(\mathrm{G})$ is the cardinality of vertices of $\mathrm{G}$. The distance between $\mathrm{u}$ and $\mathrm{v}$ denoted by $d(u, v)$ is the length of the shortest $u-v$ path in $G$. $\mathrm{G}$ is a Hamiltonian path between every pair of the distinct vertices in it at an odd distance. $\mathrm{G}$ is a Hamiltonian-t-laceable if there exists a Hamiltonian path between every pair of the vertices $\mathrm{u}$ and $\mathrm{v}$ in $\mathrm{G}$ with the property $\mathrm{d}(\mathrm{u}, \mathrm{v})=\mathrm{t}$, where $\mathrm{t}$ is a positive integer, such that $1 \leq \mathrm{t} \leq$ diamG.

The Line graph $L(G)$ of $G$ has the edges of $G$ as its vertices and two vertices of $L(G)$ are adjacent if and only if they are adjacent in G. In [3],[5],[6] and [7] the authors have studied Hamiltonian-t-laceability and Hamiltonian-t*laceability of various graph structures. In this paper we explore the Hamiltonian- $\mathrm{t}^{*}$-laceability number of Line graph $\mathrm{L}(\mathrm{G})$ and also Hamiltonian-t*-laceability of Line graph $\mathrm{L}(\mathrm{G})$ of the sun let graph, Helm graph and Gear graph.

\section{DEFINITION 1}

The Line graph $\mathrm{L}(\mathrm{G})$ of $\mathrm{G}$ is the graph of $\mathrm{E}$ in which $x, y \in E$ are adjacent as vertices if and only if they are adjacent as edges in G. In Figure 1, we display the graph G and its Line graph $L(G)$.

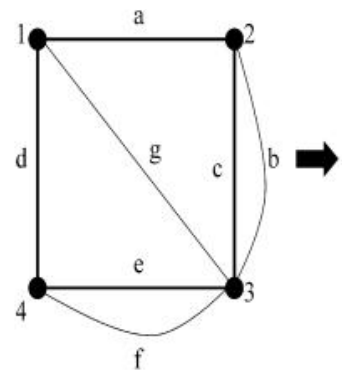

G

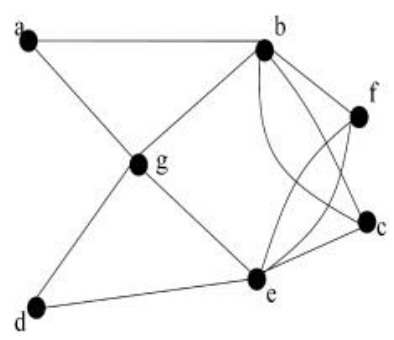

L(G)
Figure 1

\section{DEFINITION 2}

The Sun let graph $S_{n}$ is a graph with cycle where by each vertex of the cycle is attached to one pendent vertex. Each sun let graph contains r-vertices with r-edges.

In Figure 2, we display the Sun let graph $S_{n}$

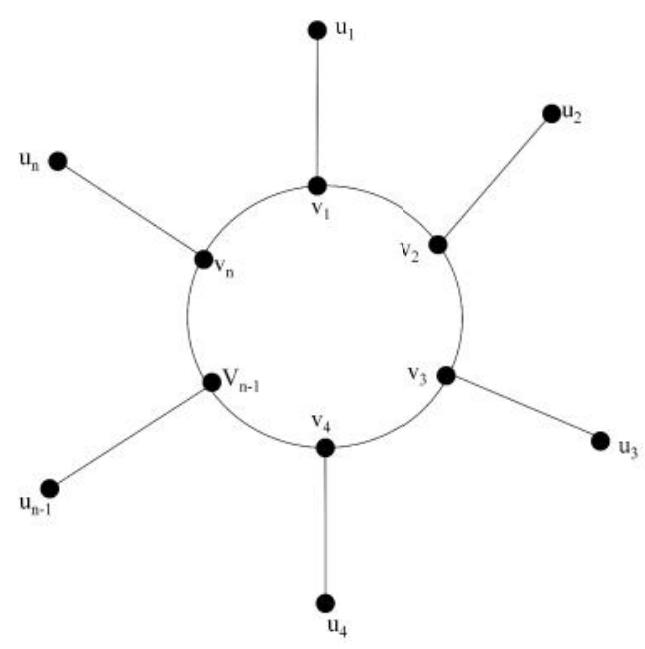

Figure 2

\section{DEFINITION 3}

The wheel graph with $\mathrm{n}$ spokes, $\mathrm{W}_{\mathrm{n}}$ is the graph that consists of an $n$-cycle and one additional vertex, say $u$, which is adjacent to all the vertices of the cycle.

In Figure 3, we display the Wheel graph $\mathrm{W}_{6}$. 


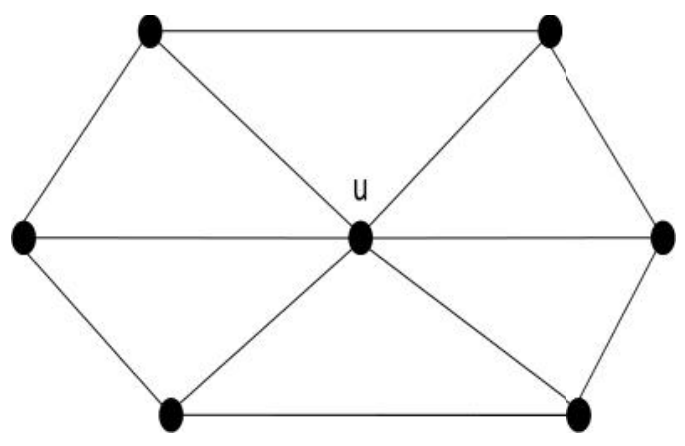

Figure 3

\section{DEFINITION 4}

The Helm graph $\mathrm{H}_{n}$ is a graph obtained from an $\mathrm{n}$-wheel graph by adjoining a pendent edge at each node of the cycle. In Figure 4, we display the Helm graph $\mathrm{H}_{\mathrm{n}}$.

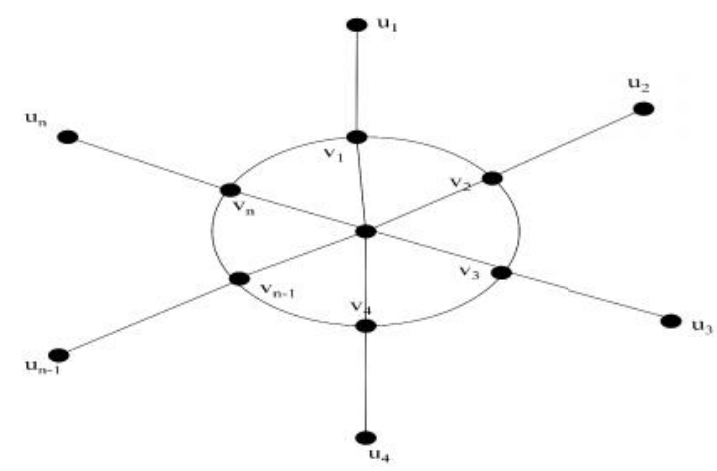

Figure 4

\section{DEFINITION 5}

The Gear graph $G_{n}$ is a wheel graph with a vertex added between each pair adjacent graph vertices of the outer cycle. The Gear graph $G_{n}$ has $2 n+1$ vertices and $3 n$ edges. In Figure 5, we display the Gear graph $\mathrm{G}_{\mathrm{n}}$.

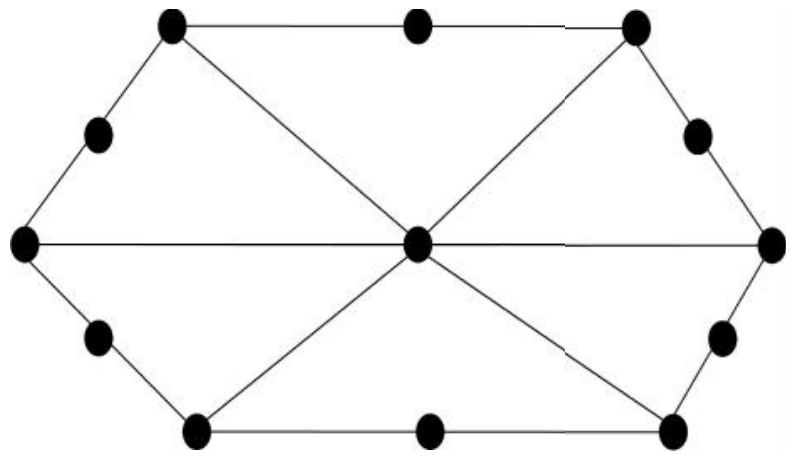

Figure 5

\section{DEFINITION 6}

For a connected graph $\mathrm{G}$, the t-laceability number $\lambda_{(t)}$ (t*laceabilty number $\left.\lambda{ }_{(t)}\right)$ is defined as the minimum number of edges to be added to $G$ such that there exist a Hamiltonian path between every pair (at least one pair) of vertices $u$ and $v$ in $G$ with the property $d(u, v)=t$ where $t$ is positive integer.

\section{RESULTS}

Theorem 2.1: The Line graph $L(G)$, where $G=S_{n}$, the sun let graph is Hamiltonian- $t^{*}$ laceable for $t=1$ and 2 if odd $n \geq 3$, where $1 \leq$ $\mathrm{t} \leq$ diamG.

Proof: Consider the graph $\mathrm{G}=\mathrm{S}_{\mathrm{n}}$, the Line graph $\mathrm{L}\left(\mathrm{S}_{\mathrm{n}}\right)$ denote the vertices $\mathrm{L}(\mathrm{G})$ by

$a_{1}, b_{1}, a_{2}, b_{2}, a_{3}, b_{3},---a_{n-1}, b_{n-1}, a_{n}, b_{n}$ for $\mathrm{t}=1$,

2 Case (i): For $t=1$

In $\mathrm{L}\left(\mathrm{S}_{\mathrm{n}}\right)$, we find that $d\left(a_{1}, b_{1}\right)=1$. and the path

$$
\begin{aligned}
& P:\left(a_{1}, b_{n}\right) \cup\left(b_{n}, a_{n}\right) \cup\left(a_{n}, b_{n-1}\right) \cup \\
& \left(b_{n-1}, a_{n-1}\right) \cup\left(a_{n-1}, b_{n-2}\right) \cup \\
& \left(a_{n-2}, b_{n-3}\right) \cup------\cup \\
& \left(b_{n-6}, a_{n-6}\right) \cup--------\cup\left(b_{3}, a_{3}\right) \cup \\
& \left(a_{3}, b_{2}\right) \cup\left(b_{2}, a_{2}\right) \cup\left(a_{2}, b_{1}\right) \text { is a Hamiltonian path. }
\end{aligned}
$$

Hence there exists a Hamiltonian path between at least one pair of vertices such that $d\left(a_{1}, b_{1}\right)=1$. Therefore $\mathrm{G}$ is a Hamiltonian- $\mathrm{t}^{*}$-laceable for $\mathrm{t}=1$.

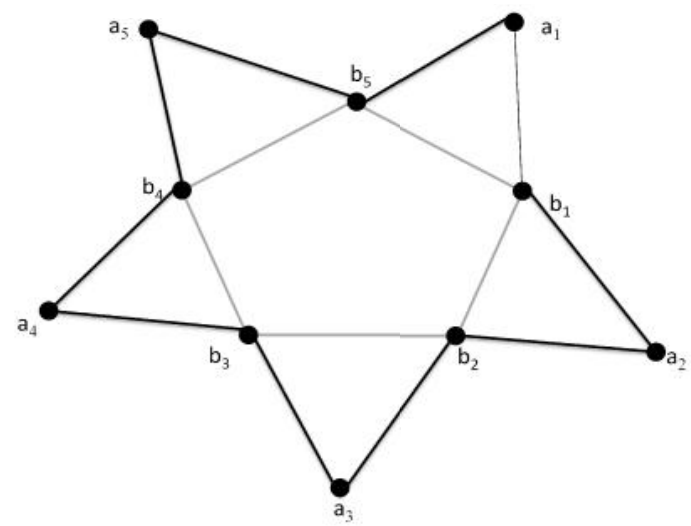

Figure 6: Hamiltonian path from the vertex $a_{1}$ to $b_{1}$ in Line graph $\mathbf{L}\left[\mathbf{S}_{\mathbf{n}}\right]$

Case (ii): For $t=2$

In $\mathrm{L}\left(\mathrm{S}_{\mathrm{n}}\right)$, we find that $d\left(a_{1}, a_{2}\right)=2$. and the path

$$
\begin{aligned}
& P:\left(a_{1}, b_{n}\right) \cup\left(b_{n}, a_{n}\right) \cup\left(a_{n}, b_{n-1}\right) \cup \\
& \left(b_{n-1}, a_{n-1}\right) \cup\left(a_{n-1}, b_{n-2}\right) \cup \\
& \left(a_{n-2}, b_{n-3}\right) \cup------\cup \\
& \left(b_{n-6}, a_{n-6}\right) \cup--------\cup\left(b_{3}, a_{3}\right) \cup \\
& \left(a_{3}, b_{2}\right) \cup\left(b_{2}, b_{1}\right) \cup\left(b_{1}, a_{2}\right)
\end{aligned}
$$

is a Hamiltonian path. Hence there exists a Hamiltonian path between at least one pair of vertices such that $d\left(a_{1}, a_{2}\right)=2$.. Therefore $\mathrm{G}$ is a Hamiltonian- $\mathrm{t}^{*}$-laceable for $\mathrm{t}=2$. 


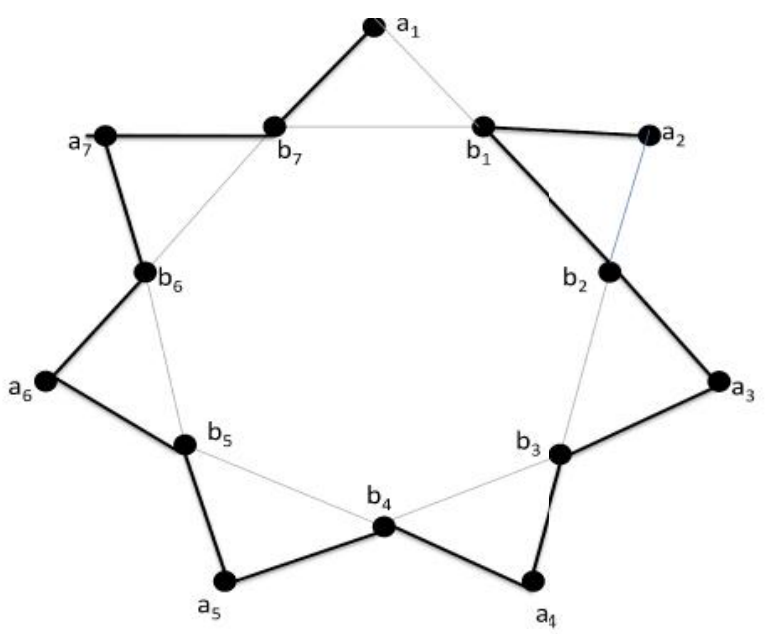

Figure 7: Hamiltonian path from the vertex $a_{1}$ to $a_{2}$ in Line graph $\mathbf{L}\left[\mathbf{S}_{7}\right]$

Lemma 2.1.1: The Line graph $L(G)$, where $G=S_{n}$ is a Hamiltonian- $t *$-laceability number if $(\lambda *(t))$ $=1$ for $t=2$ if odd $n \geq 3$ and $t=3$ if odd $n \geq 5$ where $1 \leq t \leq \operatorname{diam} G$.

Proof: Consider the graph $\mathrm{G}=\mathrm{S}_{\mathrm{n}}$, its line $\mathrm{L}\left(\mathrm{S}_{\mathrm{n}}\right)$. Here we need to establish the following cases to show that, Hamiltonian- $\mathrm{t}^{*}$ laceability number if $(\lambda *(t))=1$ for $\mathrm{t}=2$ if $\mathrm{n} \geq 3$ and $\mathrm{t}=2$ and 3 if $\mathrm{n} \geq 5$

\section{Case (i): For $t=2$}

In $\mathrm{L}\left(\mathrm{S}_{\mathrm{n}}\right)$, we find that $d\left(a_{1}, b_{2}\right)=2$ and the path

$P:\left(a_{1}, b_{1}\right) \cup\left(b_{1}, b_{n}\right) \cup\left(b_{n}, a_{n}\right) \cup\left(a_{n}, b_{n-1}\right) \cup$

$\left(b_{n-1}, a_{n-1}\right) \cup\left(a_{n-1}, b_{n-2}\right) \cup$

$\left(b_{n-2}, a_{n-2}\right) \cup---\cup\left(a_{n-9}, b_{n-10}\right) \cup$

$\left(b_{n-10}, a_{n-10}\right) \cup\left(a_{n-10}, n_{n-11}\right) \cup\left(b_{n-11}, a_{n-11}\right) \cup$

$\left(a_{n-11}, b_{n-12}\right) \cup--------\cup\left(b_{3}, a_{3}\right) \cup$

$\left(a_{3}, a_{2}\right) \cup\left(a_{2}, b_{2}\right)$ is a Hamiltonian path. Hence there exists a Hamiltonian path between at least one pair of vertices such that $d\left(a_{1}, b_{2}\right)=2$ Therefore $\mathrm{G}$ is a Hamiltonian-t*laceable for $\mathrm{t}=2$ and Laceability number $(\lambda *(t))=1$ for $\mathrm{t}=2$.

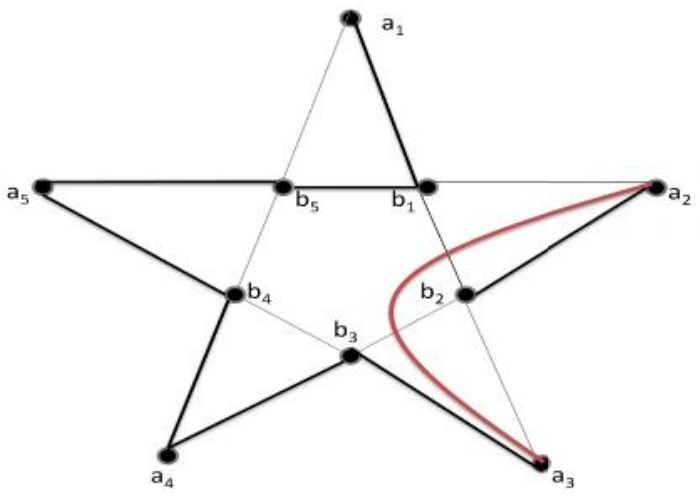

Figure 8: Hamiltonian path from the vertex $a_{1}$ to $b_{2}$ in Line graph $\mathbf{L}\left[\mathrm{S}_{5}\right]$

Case (ii): For $t=3$ if odd $n \geq 5$

In $\mathrm{L}\left(\mathrm{S}_{\mathrm{n}}\right)$, we find that $\mathrm{d}\left(\mathrm{a}_{1}, \mathrm{~b}_{3}\right)=3$ and the path

$$
\begin{aligned}
& P:\left(a_{1}, b_{1}\right) \cup\left(b_{1}, a_{2}\right) \cup\left(a_{2}, b_{2}\right) \cup\left(b_{2}, a_{3}\right) \cup \\
& \left(a_{3}, a_{n}\right) \cup\left(a_{n}, b_{n}\right) \cup---\cup\left(a_{n-2}, b_{n-3}\right) \cup \\
& \left(b_{n-3}, a_{n-3}\right) \cup------\cup\left(b_{n-10}, a_{n-10}\right) \cup \\
& \left(a_{n-10}, b_{n-11}\right) \cup\left(b_{n-11}, a_{n-11}\right) \cup\left(a_{n-11}, b_{n-12}\right) \cup \\
& \left(a_{n-11}, b_{n-12}\right) \cup--------\cup\left(b_{5}, b_{4}\right) \cup
\end{aligned}
$$

$\left(b_{4}, a_{4}\right) \cup\left(a_{4}, a_{3}\right)$ is a Hamiltonian path. Hence there exists a Hamiltonian path between at least one pair of vertices such that $\mathrm{d}\left(\mathrm{a}_{1}, \mathrm{~b}_{3}\right)=3$. Therefore $\mathrm{G}$ is a Hamiltonian- $\mathrm{t} *$-laceable for $\mathrm{t}=3$ and Laceability number $(\lambda *(t))=1$ for $\mathrm{t}=3$.

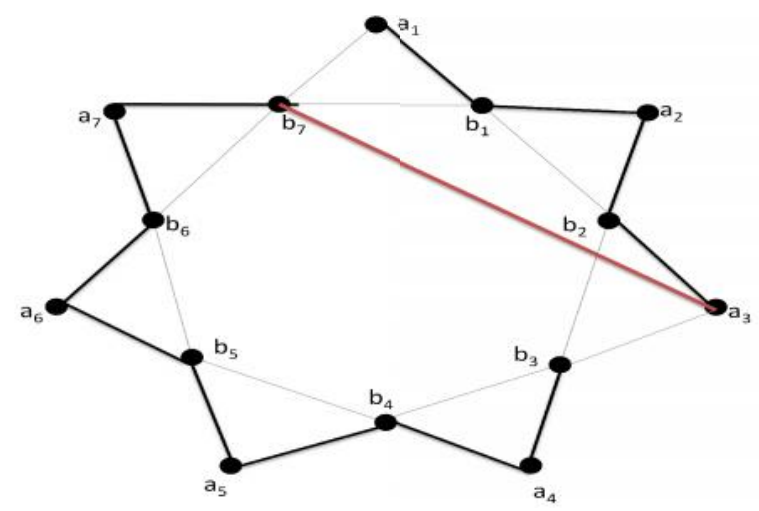

Figure 9: Hamiltonian path from the vertex $a_{1}$ to $b_{3}$ in Line graph $\mathbf{L}\left[\mathrm{S}_{7}\right]$

Theorem 2.2: The Line graph $L(G)$, where $G=S_{n}$, the sun let graph is Hamiltonian- $t^{*}$ laceable for $t=1,2$ and 3 if even $n \geq 4$, where $1 \leq \mathbf{t} \leq$ diamG.

Proof: Consider the graph $\mathrm{G}=\mathrm{S}_{\mathrm{n}}$, the Line graph $\mathrm{L}\left(\mathrm{S}_{\mathrm{n}}\right)$ denote the vertices $\mathrm{L}(\mathrm{G})$ by

$a_{1}, b_{1}, a_{2}, b_{2}, a_{3}, b_{3},---a_{n-1}, b_{n-1}, a_{n}, b_{n}$ for $\mathrm{t}=$ 1,2 and 3

Case (i): For $t=1$

In $\mathrm{L}\left(\mathrm{S}_{\mathrm{n}}\right)$, we find that $\mathrm{d}\left(\mathrm{a}_{1}, \mathrm{~b}_{1}\right)=1$ and the path

$$
\begin{aligned}
& P:\left(a_{1}, b_{n}\right) \cup\left(b_{n}, a_{n}\right) \cup\left(a_{n}, b_{n-1}\right) \cup \\
& \left(b_{n-1}, a_{n-1}\right) \cup\left(a_{n-1}, b_{n-2}\right) \cup\left(b_{n-2}, a_{n-2}\right) \cup \\
& \left(a_{n-2}, b_{n-3}\right) \cup\left(b_{n-3}, a_{n-3}\right) \cup------\cup \\
& \left(b_{n-6}, a_{n-6}\right) \cup-----------\cup\left(b_{3}, a_{3}\right) \cup
\end{aligned}
$$$$
\left(a_{3}, b_{2}\right) \cup\left(b_{2}, a_{2}\right) \cup\left(a_{2}, b_{1}\right) \text { is a Hamiltonian path. }
$$

Hence there exists a Hamiltonian path between at least one pair of vertices such that $d\left(a_{1}, b_{1}\right)=1$. Therefore $\mathrm{G}$ is a Hamiltonian- $t *$-laceable for $t=1$. 


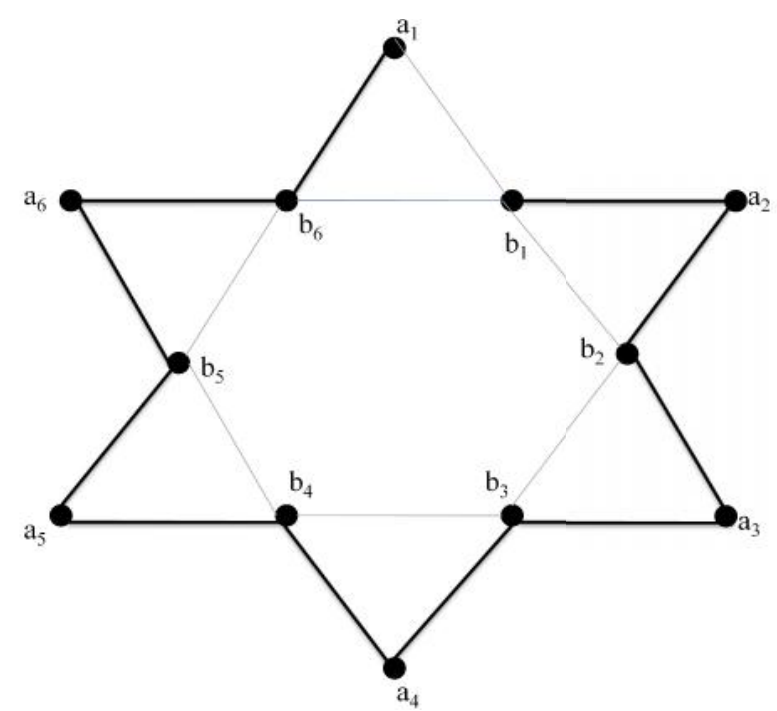

Figure 10: Hamiltonian path from the vertex $a_{1}$ to $b_{1}$ in Line graph $\mathrm{L}\left[\mathrm{S}_{6}\right]$

Case (ii): For $t=2$

In $\mathrm{L}\left(\mathrm{S}_{\mathrm{n}}\right)$, we find that $\mathrm{d}\left(\mathrm{a}_{1}, \mathrm{a}_{2}\right)=2$ and the path

$P:\left(a_{1}, b_{1}\right) \cup\left(b_{1}, b_{n}\right) \cup\left(b_{n}, a_{n}\right) \cup\left(a_{n}, b_{n-1}\right) \cup$

$\left(b_{n-1}, a_{n-1}\right) \cup\left(a_{n-1}, b_{n-2}\right) \cup--------\cup$

$\left(a_{n-5}, b_{n-6}\right) \cup------\cup$

$\left(b_{n-14}, a_{n-14}\right) \cup----------\cup$

$\left(b_{4}, a_{4}\right) \cup\left(a_{4}, b_{3}\right) \cup\left(b_{3}, a_{3}\right) \cup\left(a_{3}, b_{2}\right)$

$\cup\left(b_{2}, a_{2}\right)$ is a Hamiltonian path. Hence there exists a Hamiltonian path between at least one pair of vertices such that $d\left(a_{1}, a_{2}\right)=2$. Therefore $\mathrm{G}$ is a Hamiltonian-t*laceable for $\mathrm{t}=2$.

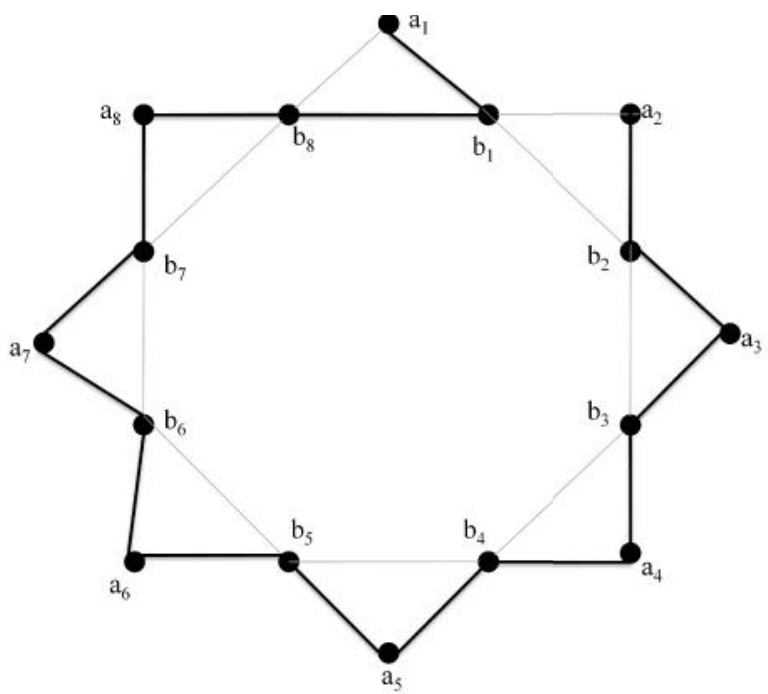

Figure 11: Hamiltonian path from the vertex $a_{1}$ to $a_{2}$ in Line graph $\mathrm{L}\left[\mathrm{S}_{8}\right]$

Lemma 2.2.2: The Line graph $L(G)$, where $G=S_{n}$ is a Hamiltonian- $t *$-laceability number, $(\lambda *(t))$
$=1$ for $t=2$ and 3 if even $n \geq 4$, where $1 \leq t \leq$ $\operatorname{diamG}$.

Proof: Consider the graph $\mathrm{G}=\mathrm{S}_{\mathrm{n}}$, its line $\mathrm{L}\left(\mathrm{S}_{\mathrm{n}}\right)$. Here we need to establish the following cases to show that, Hamiltonian-t*laceability number if $(\lambda *(t))=1$ for $\mathrm{t}=2$ and 3 if $\mathrm{n} \geq 4$

Case (i): For $t=2$

In $\mathrm{L}\left(\mathrm{S}_{\mathrm{n}}\right)$, we find that $\mathrm{d}\left(\mathrm{a}_{1}, \mathrm{~b}_{2}\right)=2$ and the path

$$
\begin{aligned}
& P:\left(a_{1}, b_{n}\right) \cup\left(b_{n}, a_{n}\right) \cup\left(a_{n}, b_{n-1}\right) \cup \\
& \left(b_{n-1}, b_{n-2}\right) \cup\left(b_{n-2}, a_{n-2}\right) \cup\left(a_{n-2}, b_{n-3}\right) \cup \\
& ---\cup\left(b_{n-8}, a_{n-8}\right) \cup \\
& \left(a_{n-8}, b_{n-9}\right) \cup-----\cup\left(b_{n-11}, b_{n-10}\right) \cup \\
& \left(b_{n-10}, a_{n-10}\right) \cup \\
& \left(a_{n-10}, b_{n-12}\right) \cup--------\cup\left(b_{4}, a_{4}\right) \cup \\
& \left(a_{4}, b_{3}\right) \cup\left(b_{3}, a_{3}\right) \cup\left(a_{3}, a_{2}\right) \cup\left(a_{2}, b_{1}\right)
\end{aligned}
$$

$\cup\left(b_{1}, b_{2}\right)$ is a Hamiltonian path. Hence there exists a Hamiltonian path between at least one pair of vertices such that $d\left(a_{1}, b_{2}\right)=2$. Therefore, $\mathrm{G}$ is a Hamiltonian- $\mathrm{t}^{*}$ laceable for $\mathrm{t}=2$ and Laceability number $(\lambda *(t))=1$ for $\mathrm{t}=2$.

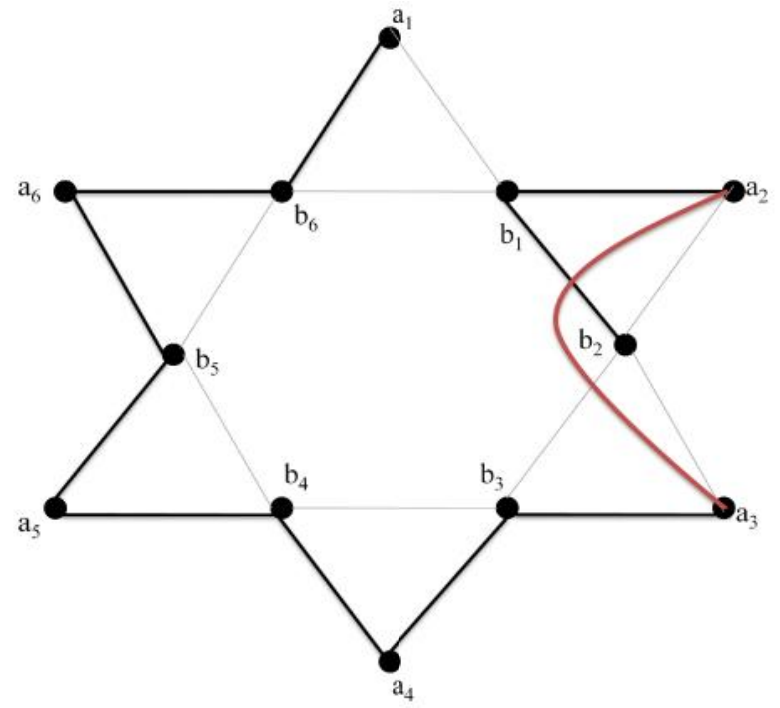

Figure 12: Hamiltonian path from the vertex $a_{1}$ to $a_{2}$ in Line graph $\mathrm{L}\left[\mathrm{S}_{6}\right]$

Case (ii): For $t=3$

In $\mathrm{L}\left(\mathrm{S}_{\mathrm{n}}\right)$, we find that $\mathrm{d}\left(\mathrm{a}_{1}, \mathrm{~b}_{3}\right)=3$ and the path

$$
\begin{aligned}
& P:\left(a_{1}, b_{1}\right) \cup\left(b_{1}, a_{2}\right) \cup\left(a_{2}, b_{2}\right) \cup\left(b_{2}, a_{3}\right) \cup \\
& \left(a_{3}, b_{n}\right) \cup\left(b_{n}, a_{n}\right) \cup\left(b_{n-1}, a_{n-1}\right) \cup \\
& \left(a_{n-1}, b_{n-2}\right) \cup-----\cup\left(a_{6}, b_{5}\right) \cup\left(b_{5}, a_{5}\right) \cup \\
& \left(a_{5}, b_{4}\right) \cup\left(b_{4}, a_{4}\right) \cup\left(a_{4}, a_{3}\right) \cup\left(a_{3}, b_{3}\right)
\end{aligned}
$$

is a Hamiltonian path. Hence there exists a Hamiltonian path between at least one pair of vertices such that $d\left(a_{1}, b_{3}\right)=3$. Therefore $\mathrm{G}$ is a Hamiltonian-t*Laceability number $(\lambda *(t))=1$ for $\mathrm{t}=3$. 


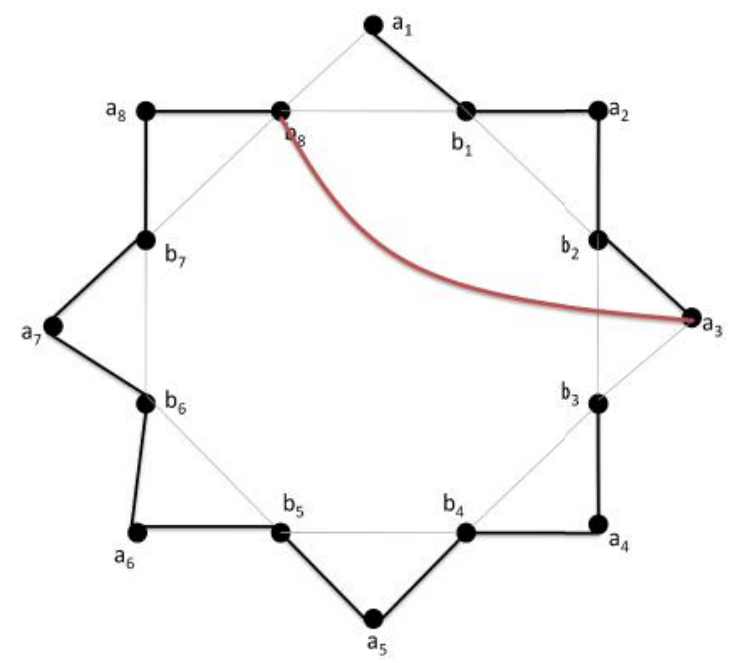

Figure 13: Hamiltonian path from the vertex $a_{1}$ to $b_{3}$ in Line graph $\mathbf{L}\left[\mathrm{S}_{8}\right]$

\section{Remark}

If $\mathrm{n} \geq 4$, the distance from $\mathrm{d}\left(\mathrm{a}_{1}, \mathrm{a}_{3}\right)=3$ is a Hamiltonian- $\mathrm{t}^{*}$ laceable for $\mathrm{t}=3$ and its laceability number $(\lambda *(t))=1$ for $\mathrm{t}=3$, then the path

$$
\begin{aligned}
& P:\left(a_{1}, b_{1}\right) \cup\left(b_{1}, b_{n}\right) \cup\left(b_{n}, a_{n}\right) \cup\left(a_{n}, b_{n-1}\right) \cup \\
& \left(a_{n-1}, b_{n-2}\right) \cup-----\cup\left(a_{6}, b_{5}\right) \cup\left(b_{5}, a_{5}\right) \cup \\
& \left(a_{5}, b_{4}\right) \cup\left(b_{4}, a_{4}\right) \cup\left(a_{4}, b_{3}\right) \cup\left(b_{3}, b_{2}\right) \cup \\
& \left(b_{2}, a_{2}\right) \cup\left(a_{2}, a_{3}\right) \text { is a Hamiltonian path }
\end{aligned}
$$

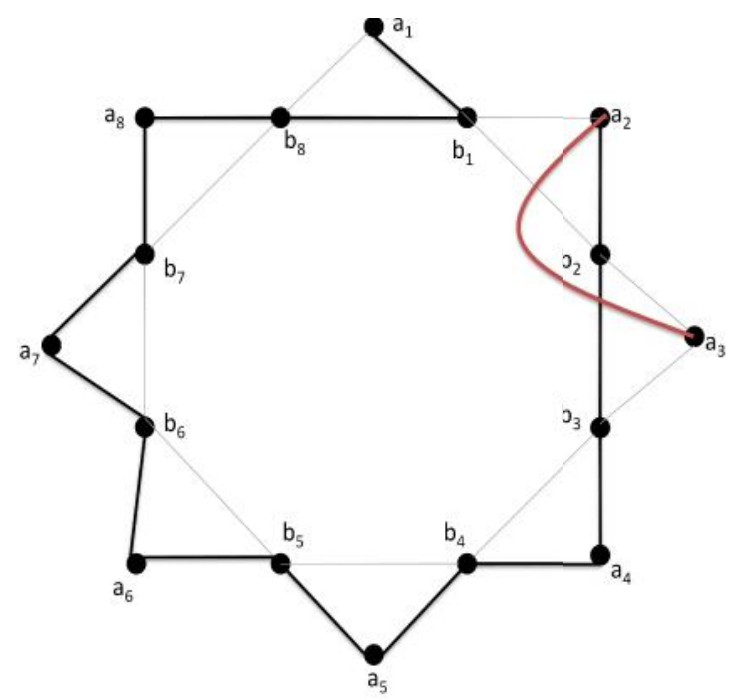

Figure 14: Hamiltonian path from the vertex $a_{1}$ to $a_{3}$ in Line graph $\mathbf{L}\left[\mathrm{S}_{\mathbf{8}}\right]$

Theorem 2.3: The Line graph $L(G)$, where $\mathbf{G}=\mathrm{H}_{\mathrm{n}}, \quad \mathrm{n} \geq 3$, the Helm graph is Hamiltonian-t*-laceable for $t=1,2$ and 3,with diameter 3 .

Proof: Consider the graph $\mathrm{G}=\mathrm{H}_{\mathrm{n}}$, its Line graph is denoted by $\mathrm{L}\left(\mathrm{H}_{\mathrm{n}}\right)$ denote the vertices of $\mathrm{L}(\mathrm{G})$ by $a_{1}, b_{1}, c_{1}, a_{2}, b_{2}, c_{2}$, $a_{3}, b_{3}, c_{3}, a_{4}, b_{4}, c_{4},------, a_{n-1}, b_{n-1}, c_{n-1}$, $a_{n}, b_{n}, c_{n}$. Hence we need to establish the following claims to show that $\mathrm{G}$ is a Hamiltonian-t*-laceable for $\mathrm{t}=1,2$ and 3 with diameter 3 .

In Figure 15, we display the Helm graph $\mathrm{H}_{\mathrm{n}}$.

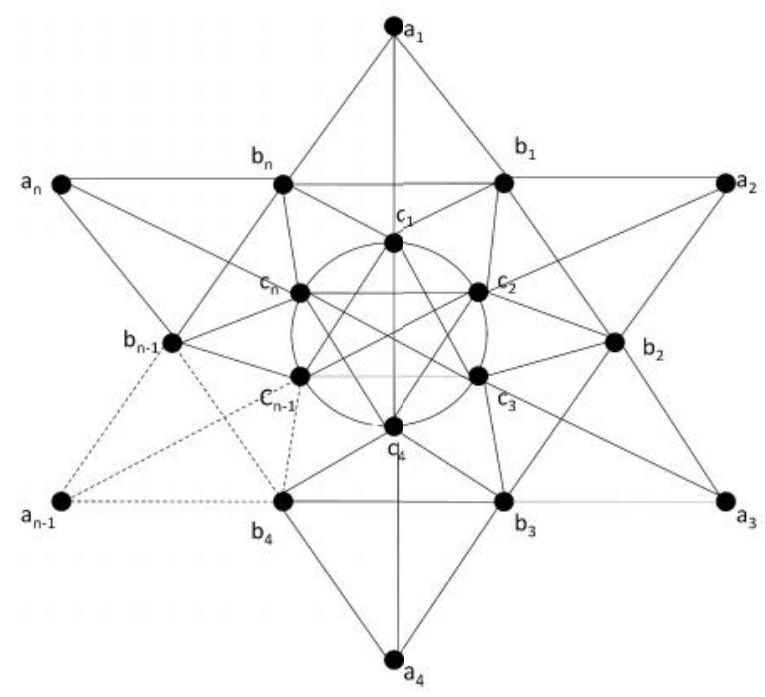

Figure 15

Claim 2.3.1: For $t=1$

Case (i): If $n$ is odd

In $\mathrm{L}\left(\mathrm{H}_{\mathrm{n}}\right)$, we find that $d\left(a_{1}, c_{1}\right)=1$ and the path

$P:\left(a_{1}, b_{1}\right) \cup\left(b_{1}, b_{n}\right) \cup\left(b_{n}, c_{n}\right) \cup\left(c_{n}, a_{n}\right) \cup$

$\left(a_{n}, b_{n-1}\right) \cup\left(b_{n-1}, c_{n-1}\right) \cup\left(c_{n-1}, a_{n-1}\right) \cup$

$\left(a_{n-1}, b_{n-2}\right) \cup\left(b_{n-2}, c_{n-2}\right) \cup\left(c_{n-2}, a_{n-2}\right) \cup$

$\left(a_{n-2}, b_{n-3}\right) \cup\left(b_{n-3}, c_{n-3}\right) \cup\left(c_{n-3}, a_{n-3}\right) \cup$

$----\cup\left(b_{3}, c_{3}\right) \cup\left(c_{3}, a_{3}\right) \cup\left(a_{3}, b_{2}\right) \cup$

$\left(b_{2}, a_{2}\right) \cup\left(a_{2}, c_{2}\right) \cup\left(c_{2}, c_{1}\right)$ is a Hamiltonian path. Hence there exists a Hamiltonian path between at least one pair of vertices such that $d\left(a_{1}, c_{1}\right)=1$. Therefore $\mathrm{G}$ is a Hamiltonian- $\mathrm{t}^{*}$ - Laceable for $\mathrm{t}=1$.

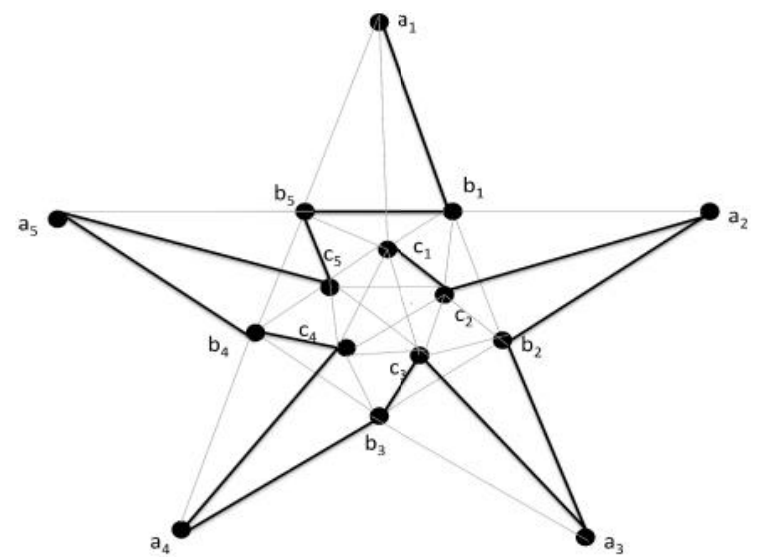

Figure 16: Hamiltonian path from the vertex $a_{1}$ to $c_{1}$ in Line graph $\mathrm{L}\left[\mathrm{H}_{5}\right]$

Case (ii): If $n$ is even

In $\mathrm{L}\left(\mathrm{H}_{\mathrm{n}}\right)$, we find that $d\left(a_{1}, c_{1}\right)=1$ and the path 
$P:\left(a_{1}, b_{n}\right) \cup\left(b_{n}, a_{n}\right) \cup\left(a_{n}, c_{n}\right) \cup\left(c_{n}, b_{n-1}\right) \cup$

$\left(b_{n-1}, a_{n-1}\right) \cup\left(a_{n-1}, c_{n-1}\right) \cup\left(c_{n-1}, b_{n-2}\right) \cup$

$\left(b_{n-2}, a_{n-2}\right) \cup----\cup\left(b_{4}, a_{4}\right) \cup\left(a_{4}, c_{4}\right) \cup$

$\left(c_{4}, b_{4}\right) \cup\left(b_{4}, b_{3}\right) \cup\left(b_{3}, a_{3}\right) \cup\left(a_{3}, c_{3}\right) \cup$

$\left(c_{3}, b_{2}\right) \cup\left(b_{2}, a_{2}\right) \cup\left(a_{2}, c_{2}\right) \cup\left(c_{2}, b_{1}\right)$

$\cup\left(b_{2}, c_{1}\right)$ is a Hamiltonian path. Hence there exists a Hamiltonian path between at least one pair of vertices such that $d\left(a_{1}, c_{1}\right)=1$. Therefore $\mathrm{G}$ is a Hamiltonian-t*Laceable for $\mathrm{t}=1$.

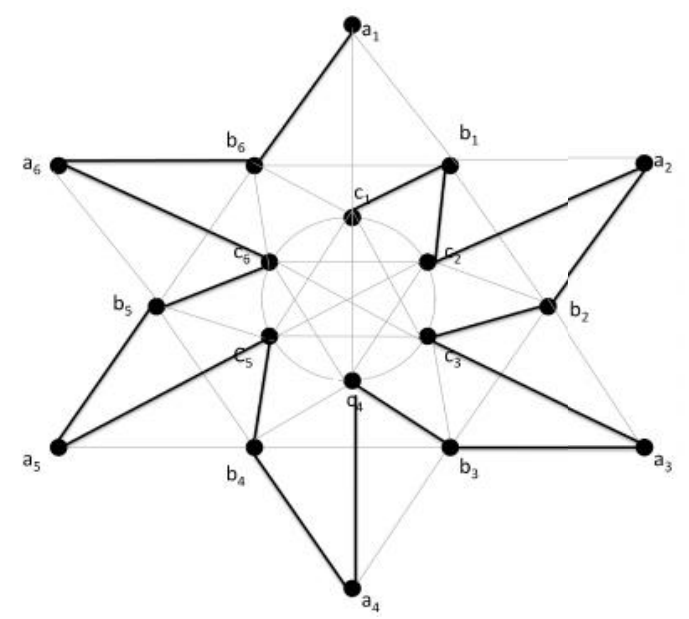

Figure 17: Hamiltonian path from the vertex $a_{1}$ to $c_{1}$ in Line graph $\mathrm{L}\left[\mathrm{H}_{6}\right]$

Claim 2.3.2: For $t=2$

Case (iii): If $n$ is odd

In $\mathrm{L}\left(\mathrm{H}_{\mathrm{n}}\right)$, we find that $d\left(a_{1}, a_{2}\right)=2$ and the path

$P:\left(a_{1}, c_{1}\right) \cup\left(c_{1}, b_{n}\right) \cup\left(b_{n}, c_{n}\right) \cup\left(c_{n}, a_{n}\right) \cup$

$\left(a_{n}, b_{n-1}\right) \cup\left(b_{n-1}, c_{n-1}\right) \cup\left(c_{n-1}, a_{n-1}\right) \cup$

$\left(a_{n-1}, b_{n-2}\right) \cup\left(b_{n-2}, c_{n-2}\right) \cup\left(c_{n-2}, a_{n-2}\right) \cup$

$-------\cup\left(c_{n-5}, a_{n-5}\right) \cup-----\cup$

$\left(b_{3}, c_{3}\right) \cup\left(c_{3}, a_{3}\right) \cup\left(a_{3}, b_{2}\right) \cup\left(b_{2}, c_{2}\right) \cup$

$\left(c_{2}, b_{1}\right) \cup\left(b_{1}, a_{2}\right)$ is a Hamiltonian path. Hence there exists a Hamiltonian path between at least one pair of vertices such that $d\left(a_{1}, a_{2}\right)=2$ Therefore $\mathrm{G}$ is a Hamiltonian- $\mathrm{t}^{*}$ Laceable for $\mathrm{t}=2$.

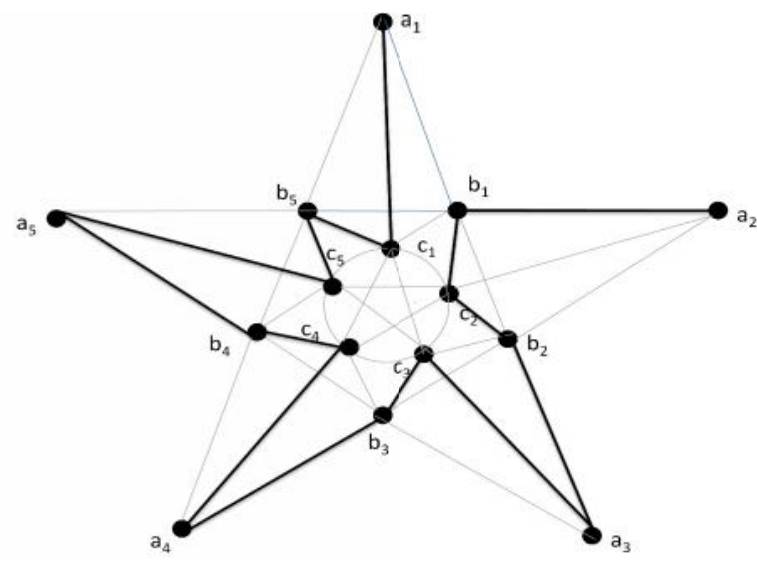

Figure 18: Hamiltonian path from the vertex $a_{1}$ to $a_{2}$ in Line graph $\mathrm{L}\left[\mathrm{H}_{5}\right]$

Case (iv): If $n$ is even

In $\mathrm{L}\left(\mathrm{H}_{\mathrm{n}}\right)$, we find that $d\left(a_{1}, a_{2}\right)=2$ and the path

$$
\begin{aligned}
& P:\left(a_{1}, b_{n}\right) \cup\left(b_{n}, c_{n}\right) \cup\left(c_{n}, a_{n}\right) \cup\left(a_{n}, b_{n-1}\right) \cup \\
& \left(b_{n-1}, c_{n-1}\right) \cup\left(c_{n-1}, a_{n-1}\right) \cup\left(a_{n-1}, b_{n-2}\right) \cup \\
& \left(b_{n-2}, c_{n-2}\right) \cup\left(c_{n-2}, a_{n-2}\right) \cup \\
& ----\cup\left(b_{n-4}, a_{n-4}\right) \cup-----\cup\left(b_{4}, c_{4}\right) \cup \\
& \left(c_{4}, a_{4}\right) \cup\left(a_{4}, b_{3}\right) \cup\left(b_{3}, c_{3}\right) \cup\left(c_{3}, a_{3}\right) \cup \\
& \left(a_{3}, b_{2}\right) \cup\left(b_{2}, c_{2}\right) \cup\left(c_{2}, c_{1}\right) \cup\left(c_{1}, b_{1}\right) \cup \\
& \left(b_{1}, a_{2}\right)
\end{aligned}
$$

is a Hamiltonian path. Hence there exists a Hamiltonian path between at least one pair of vertices such that $d\left(a_{1}, a_{2}\right)=2 \mathrm{~d}\left(\mathrm{a}_{1}, \mathrm{a}_{2}\right)=2$. Therefore $\mathrm{G}$ is a Hamiltonian- $\mathrm{t}^{*}$ Laceable for $\mathrm{t}=2$.

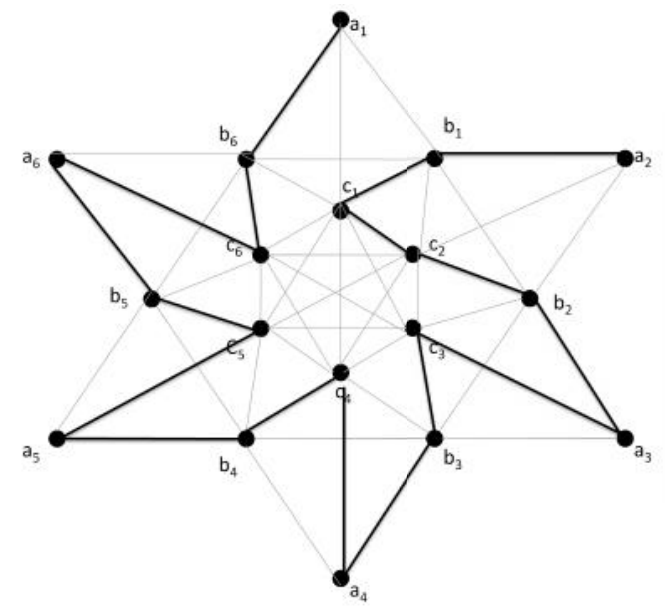

Figure 19: Hamiltonian path from the vertex $a_{1}$ to $a_{2}$ in Line graph $\mathrm{L}\left[\mathrm{H}_{6}\right]$

Claim 3: For $t=3$

Case (v): If $n$ is odd

In $\mathrm{L}\left(\mathrm{H}_{\mathrm{n}}\right)$, we find that $d\left(a_{1}, a_{3}\right)=3$ and the path

$$
\begin{aligned}
& P:\left(a_{1}, b_{1}\right) \cup\left(b_{1}, b_{n}\right) \cup\left(b_{n}, c_{n}\right) \cup\left(c_{n}, a_{n}\right) \cup \\
& \left(a_{n}, b_{n-1}\right) \cup\left(b_{n-1}, a_{n-1}\right) \cup\left(a_{n-1}, b_{n-2}\right) \cup
\end{aligned}
$$


$\left(b_{n-2}, c_{n-2}\right) \cup\left(c_{n-2}, a_{n-2}\right) \cup\left(a_{n-2}, b_{n-3}\right) \cup$

$----\cup\left(c_{n-12}, a_{n-12}\right) \cup-----\cup\left(b_{3}, c_{3}\right) \cup$

$\left(c_{3}, c_{2}\right) \cup\left(c_{2}, a_{2}\right) \cup\left(a_{2}, b_{2}\right) \cup\left(b_{2}, a_{3}\right)$

is a Hamiltonian path. Hence there exists a Hamiltonian path between at least one pair of vertices such that $d\left(a_{1}, a_{3}\right)=3 \mathrm{~d}\left(\mathrm{a}_{1}, \mathrm{a}_{3}\right)=3$. Therefore $\mathrm{G}$ is a Hamiltonian- $\mathrm{t}^{*}$ Laceable for $\mathrm{t}=3$.

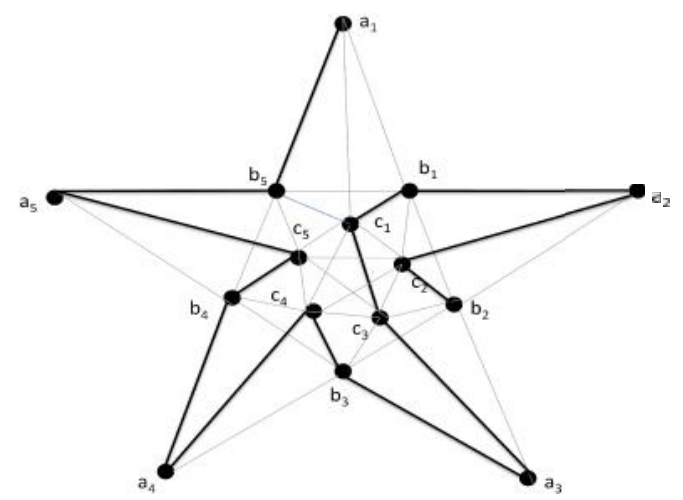

Figure 20: Hamiltonian path from the vertex $a_{1}$ to $b_{2}$ in Line graph $\mathbf{L}\left[\mathrm{H}_{5}\right]$

Case (vi): If $n$ is even

In $\mathrm{L}\left(\mathrm{H}_{\mathrm{n}}\right)$, we find that $d\left(a_{1}, a_{3}\right)=3$ and the path

$P:\left(a_{1}, b_{n}\right) \cup\left(b_{n}, a_{n}\right) \cup\left(a_{n}, c_{n}\right) \cup\left(c_{n}, b_{n-1}\right) \cup$

$\left(b_{n-1}, a_{n-1}\right) \cup\left(a_{n-1}, c_{n-1}\right) \cup\left(c_{n-1}, b_{n-2}\right) \cup$

$\left(b_{n-2}, a_{n-2}\right) \cup\left(a_{n-2}, c_{n-2}\right) \cup$

$----\cup\left(a_{n-7}, c_{n-7}\right) \cup-----\cup\left(b_{4}, a_{4}\right) \cup$

$\left(a_{4}, c_{4}\right) \cup\left(c_{4}, b_{5}\right) \cup\left(b_{5}, a_{5}\right) \cup-------\cup$

$\left(c_{2}, b_{1}\right) \cup\left(b_{1}, c_{1}\right) \cup\left(c_{1}, c_{3}\right) \cup\left(c_{3}, a_{3}\right)$

is a Hamiltonian path. Hence there exists a Hamiltonian path between at least one pair of vertices such that $d\left(a_{1}, a_{3}\right)=3$. Therefore $\mathrm{G}$ is a Hamiltonian-t*- Laceable for $\mathrm{t}=3$.

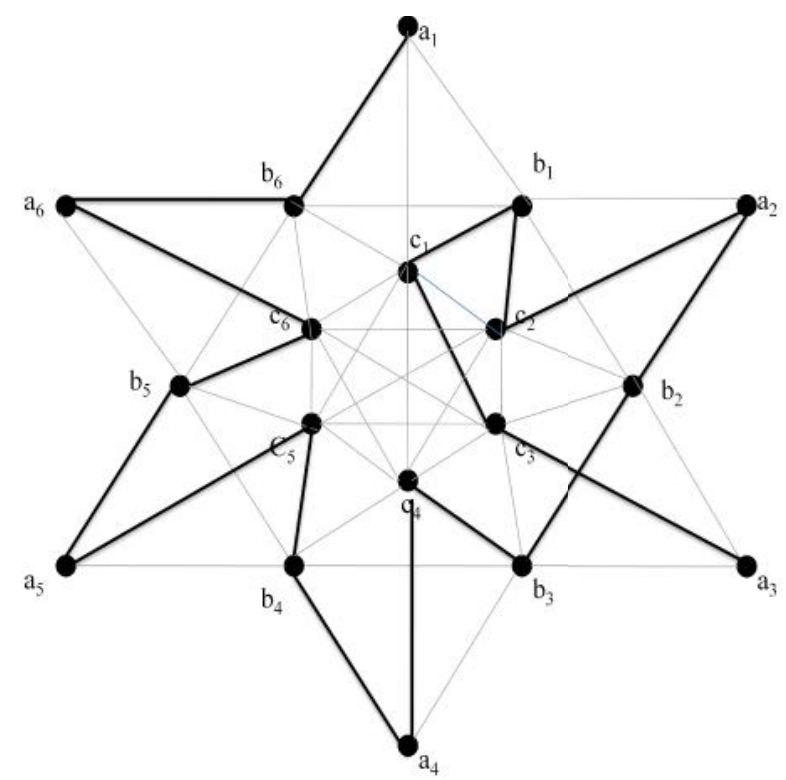

Figure 21: Hamiltonian path from the vertex $a_{1}$ to $a_{3}$ in Line graph $\mathrm{L}\left[\mathrm{H}_{6}\right]$

Theorem 2.4 The Line graph $L$ (G), where $G=G_{n}, \quad n \geq 4$, the Gear graph is Hamiltonian- $t *$-laceable for $t=1,2$ and 3 , with diameter 3

Proof: Consider the graph $\mathrm{G}=\mathrm{G}_{\mathrm{n}}$, its Line graph is denoted by $\mathrm{L}\left(\mathrm{G}_{\mathrm{n}}\right)$ denote the vertices of $\mathrm{L}(\mathrm{G})$ by

$a_{1}, a_{2}, a_{3}, a_{4},-----, a_{n-1}, a_{n}$. Hence we need to

establish the following claims to show that $\mathrm{G}$ is a

Hamiltonian- $\mathrm{t}^{*}$-laceable for $\mathrm{t}=1,2$ and 3 with diameter 3 .

Claim 1: For $\mathbf{t}=\mathbf{1}$

Case (i): If $n$ is odd

In $\mathrm{L}\left(\mathrm{G}_{\mathrm{n}}\right)$, we find that $d\left(a_{0}, a_{1}\right)=1$ and the path

$P:\left(a_{0}, a_{2 n-2}\right) \cup\left(a_{2 n-2}, a_{3 n-4}\right) \cup\left(a_{2 n-3}, a_{2 n-4}\right) \cup$

$\left(a_{2 n-9}, a_{3 n-9}\right) \cup-------\cup\left(a_{16}, a_{15}\right) \cup$

$\left(a_{15}, a_{2 n+5}\right) \cup----\cup\left(a_{14}, a_{13}\right) \cup-----\cup$

$\left(a_{6}, a_{2 n}\right) \cup\left(a_{2 n}, a_{5}\right) \cup\left(a_{5}, a_{4}\right) \cup\left(a_{3}, a_{2 n-1}\right) \cup$

$\left(a_{2 n-1}, a_{2}\right) \cup\left(a_{2}, a_{1}\right)$ is a Hamiltonian path. Hence there exists a Hamiltonian path between at least one pair of vertices such that $d\left(a_{0}, a_{1}\right)=1$. Therefore $\mathrm{G}$ is a Hamiltonian- $\mathrm{t} *$ - Laceable for $\mathrm{t}=1$.

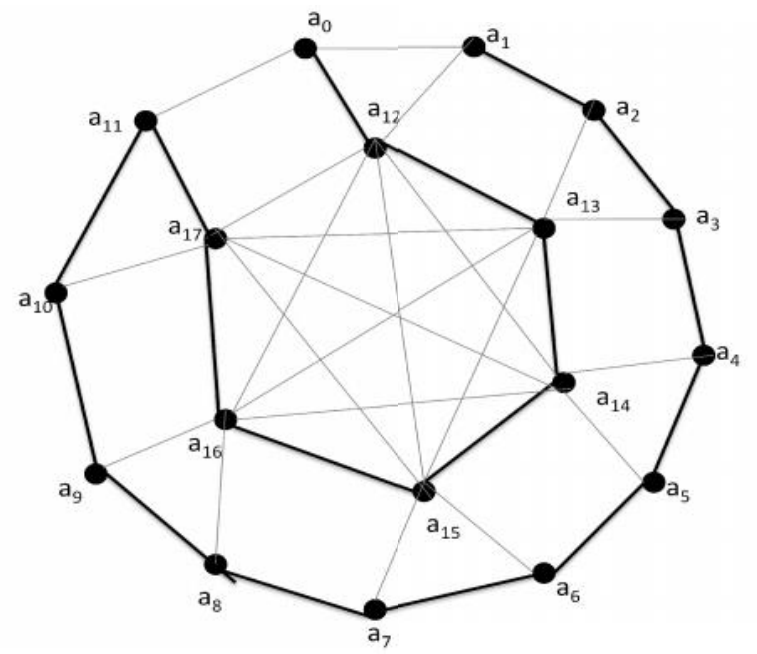

Figure 22: Hamiltonian path from the vertex $a_{0}$ to $a_{1}$ in Line graph $\mathbf{L}\left[\mathbf{G}_{7}\right]$

Case (ii): If $n$ is even

In $\mathrm{L}\left(\mathrm{G}_{\mathrm{n}}\right)$, we find that $d\left(a_{0}, a_{1}\right)=1$ and the path

$$
P:\left(a_{0}, a_{2 n-2}\right) \cup\left(a_{2 n-2}, a_{2 n-1}\right) \cup\left(a_{2 n-1}, a_{2 n}\right) \cup
$$$$
\left(a_{2 n}, a_{2 n+1}\right) \cup\left(a_{2 n+1}, a_{2 n+2}\right) \cup\left(a_{2 n+2}, a_{2 n+3}\right) \cup
$$$$
----\cup\left(a_{15}, a_{14}\right) \cup-----\cup\left(a_{8}, a_{7}\right) \cup
$$$$
\left(a_{7}, a_{6}\right) \cup-----\cup\left(a_{4}, a_{3}\right) \cup\left(a_{3}, a_{2}\right) \cup
$$

$\left(a_{2}, a_{1}\right)$ is a Hamiltonian path. Hence there exists a Hamiltonian path between at least one pair of vertices such that $d\left(a_{0}, a_{1}\right)=1$. Therefore $\mathrm{G}$ is a Hamiltonian-t* Laceable for $\mathrm{t}=1$. 


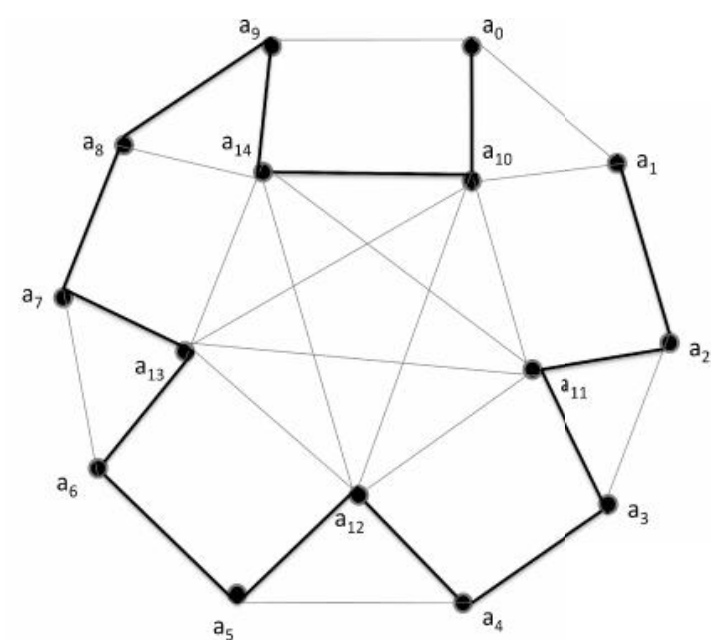

Figure 23: Hamiltonian path from the vertex $a_{0}$ to $a_{1}$ in Line graph $\mathbf{L}\left[\mathbf{G}_{6}\right]$

Claim 2.4.1: For $t=2$

Case (i): If $n$ is odd

In $\mathrm{L}\left(\mathrm{G}_{\mathrm{n}}\right)$, we find that $d\left(a_{0}, a_{2}\right)=2$ and the path

$P:\left(a_{0}, a_{1}\right) \cup\left(a_{1}, a_{2 n-2}\right) \cup\left(a_{2 n-2}, a_{2 n-1}\right) \cup$

$\left(a_{2 n-1}, a_{2 n}\right) \cup\left(a_{2 n}, a_{2 n+1}\right) \cup--------$

$------\cup\left(a_{2 n-3}, a_{2 n-4}\right) \cup--------$

$----\cup\left(a_{15}, a_{14}\right) \cup\left(a_{14}, a_{13}\right) \cup\left(a_{13}, a_{12}\right) \cup$

$\left(a_{12}, a_{11}\right) \cup\left(a_{11}, a_{10}\right) \cup\left(a_{10}, a_{9}\right) \cup\left(a_{9}, a_{8}\right) \cup$

$\left(a_{8}, a_{7}\right) \cup\left(a_{7}, a_{6}\right) \cup\left(a_{6}, a_{5}\right) \cup\left(a_{5}, a_{4}\right) \cup$

$\left(a_{4}, a_{3}\right) \cup\left(a_{3}, a_{2}\right)$ is a Hamiltonian path. Hence there exists a Hamiltonian path between at least one pair of vertices such that $d\left(a_{0}, a_{2}\right)=2$. Therefore $\mathrm{G}$ is a Hamiltonian-t*Laceable for $\mathrm{t}=2$

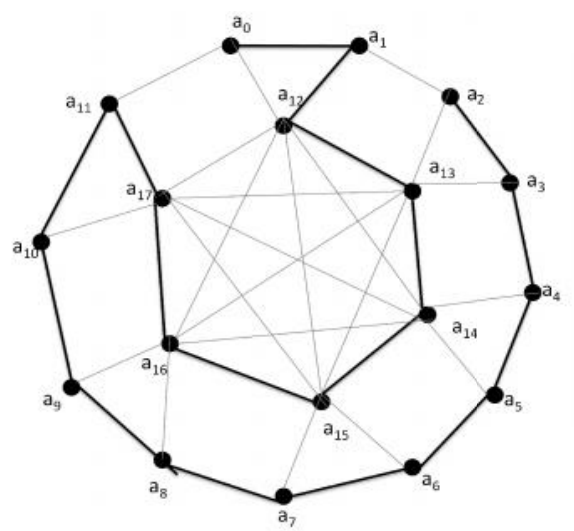

Figure 24: Hamiltonian path from the vertex $a_{0}$ to $a_{2}$ in Line graph $\mathbf{L}\left[\mathbf{G}_{7}\right]$

Case (ii): If $n$ is even

In $\mathrm{L}\left(\mathrm{G}_{\mathrm{n}}\right)$, we find that $d\left(a_{0}, a_{2}\right)=2$ and the path

$$
\begin{aligned}
& P:\left(a_{0}, a_{1}\right) \cup\left(a_{1}, a_{2 n-2}\right) \cup\left(a_{2 n-2}, a_{2 n-1}\right) \cup \\
& \left(a_{2 n-1}, a_{2 n}\right) \cup\left(a_{2 n}, a_{2 n+1}\right) \cup-------- \\
& ------\cup\left(a_{2 n-3}, a_{2 n-4}\right) \cup-------- \\
& ----\cup\left(a_{15}, a_{14}\right) \cup\left(a_{14}, a_{13}\right) \cup\left(a_{13}, a_{12}\right) \cup \\
& \left(a_{12}, a_{11}\right) \cup\left(a_{11}, a_{10}\right) \cup\left(a_{10}, a_{9}\right) \cup\left(a_{9}, a_{8}\right) \cup \\
& \left(a_{8}, a_{7}\right) \cup\left(a_{7}, a_{6}\right) \cup\left(a_{6}, a_{5}\right) \cup\left(a_{5}, a_{4}\right) \cup
\end{aligned}
$$

$\left(a_{4}, a_{3}\right) \cup\left(a_{3}, a_{2}\right)$ is a Hamiltonian path. Hence there exists a Hamiltonian path between at least one pair of vertices such that $d\left(a_{0}, a_{2}\right)=2$. Therefore $\mathrm{G}$ is a Hamiltonian- $\mathrm{t}^{*}$ Laceable for $\mathrm{t}=2$.

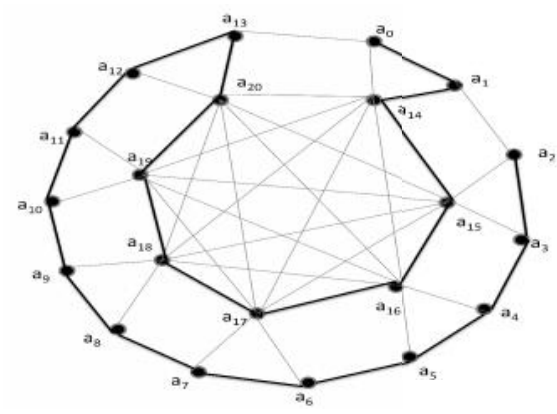

Figure 25: Hamiltonian path from the vertex $a_{0}$ to $a_{2}$ in Line graph $\mathbf{L}\left[\mathbf{G}_{8}\right]$

Claim 3.4.2: For $t=3$

Case (i): If $n$ is odd

In $\mathrm{L}\left(\mathrm{G}_{\mathrm{n}}\right)$, we find that $d\left(a_{0}, a_{3}\right)=3$ and the path

$$
\begin{aligned}
& P:\left(a_{0}, a_{1}\right) \cup\left(a_{1}, a_{2}\right) \cup\left(a_{2}, a_{2 n-1}\right) \cup \\
& \left(a_{2 n-1}, a_{2 n-2}\right) \cup\left(a_{2 n-2}, a_{2 n+7}\right) \cup\left(a_{2 n+7}, a_{2 n-3}\right) \cup \\
& \left(a_{2 n-3}, a_{2 n-4}\right) \cup------------ \\
& ------\cup\left(a_{14}, a_{13}\right) \cup \\
& ----\cup\left(a_{2 n+3}, a_{11}\right) \cup\left(a_{11}, a_{10}\right) \cup \\
& \left(a_{10}, a_{9}\right) \cup---------\cup \\
& \left(a_{2 n+2}, a_{2 n+3}\right) \cup------\cup\left(a_{7}, a_{6}\right) \cup \\
& \left(a_{6}, a_{5}\right) \cup\left(a_{5}, a_{2 n}\right) \cup\left(a_{2 n}, a_{4}\right) \cup\left(a_{4}, a_{3}\right) \text { is a }
\end{aligned}
$$
Hamiltonian path. Hence there exists a Hamiltonian path between at least one pair of vertices such that $d\left(a_{0}, a_{3}\right)=3$. Therefore $\mathrm{G}$ is a Hamiltonian-t*- Laceable for $\mathrm{t}=3$. 


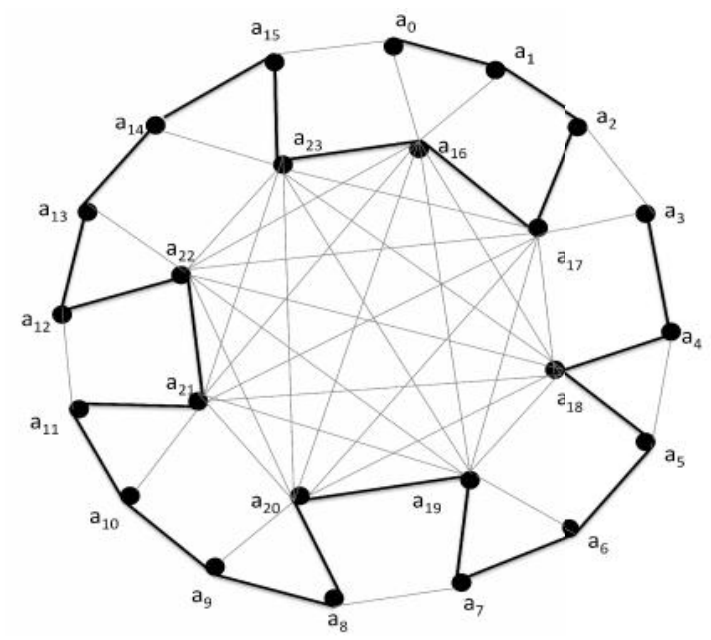

Figure 26: Hamiltonian path from the vertex $a_{0}$ to $a_{3}$ in Line graph $\mathbf{L}\left[\mathbf{G}_{9}\right]$

Case (ii): If $n$ is even

In $\mathrm{L}\left(\mathrm{G}_{\mathrm{n}}\right)$, we find that $d\left(a_{0}, a_{3}\right)=3$ and the path

$P:\left(a_{0}, a_{1}\right) \cup\left(a_{1}, a_{2}\right) \cup\left(a_{2}, a_{2 n-1}\right) \cup$

$\left(a_{2 n-1}, a_{2 n-2}\right) \cup\left(a_{2 n-2}, a_{3 n-4}\right) \cup\left(a_{3 n-4}, a_{2 n-3}\right) \cup$

$\left(a_{19}, a_{18}\right) \cup\left(a_{18}, a_{3 n-5}\right) \cup$

$------\cup\left(a_{17}, a_{16}\right) \cup\left(a_{16}, a_{15}\right) \cup$

$\left(a_{15}, a_{14}\right) \cup\left(a_{14}, a_{2 n+5}\right) \cup\left(a_{2 n+5}, a_{2 n+4}\right) \cup$

$\left(a_{2 n+4}, a_{13}\right) \cup------\cup\left(a_{2 n+3}, a_{2 n+2}\right) \cup$

$\left(a_{9}, a_{8}\right) \cup\left(a_{8}, a_{7}\right) \cup\left(a_{7}, a_{6}\right) \cup\left(a_{6}, a_{2 n+1}\right) \cup$

$\left(a_{2 n+1}, a_{2 n}\right) \cup\left(a_{2 n}, a_{5}\right) \cup\left(a_{5}, a_{4}\right) \cup\left(a_{4}, a_{3}\right)$ is a

Hamiltonian path. Hence there exists a Hamiltonian path between at least one pair of vertices such that $d\left(a_{0}, a_{3}\right)=3$. Therefore $\mathrm{G}$ is a Hamiltonian-t*- Laceable for $\mathrm{t}=3$.

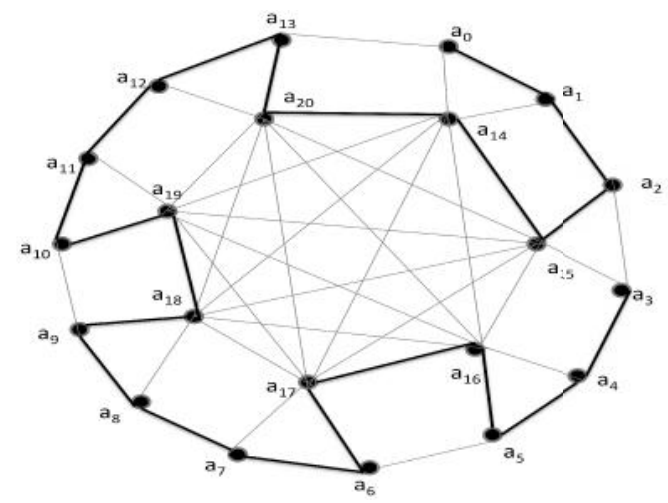

Figure 27: Hamiltonian path from the vertex $a_{0}$ to $a_{3}$ in Line graph $\mathbf{L}\left[\mathbf{G}_{8}\right]$

\section{CONCLUSION}

In this present study, the concept of Hamiltonian-t*laceability in line graphs and $t^{*}$-laceability number ( are investigated. In our further work, Laceability of total graphs of other kind is to be proposed.

\section{ACKNOWLEDGMENTS}

The first author thankfully acknowledges the support and encouragement provided by the Management and staff of the department of Mathematics. Gopalan college of Engineering and Management, Bangalore, Karnataka. The authors are also thankful to the management and R\&D centre, Department of Mathematics, Dr. Ambedkar Institute of Technology, Bangalore, Karnata.

\section{REFERENCES}

[1] Chartrand, H.Hevia, E.B.M. Schultz,Subgraph distance graphs defined by Edge transfers, Discrete math. 170(1997)63-79.

[2] Bayindureng $\mathrm{Wu}$, Jixiang Meng, Hamiltonian Jump graphs, Discrete Mathematics 289(2004)95-106.

[3] Leena N. shenoy and R.Murali, Laceability on a class of Regular Graphs, International Journal of computational Science and Mathematics, volume2, Number 3 (2010), pp 397- 406 .

[4] Girisha.A and R.Murali, Hamiltonian laceability in a class of 4-Regular Graphs, IOSR Journal of Mathematics, Volume 4, Issue 1 (Nov.- Dec. 2012), pp $07-12 .$.

[5] G.Manjunath and R.Murali, Hamiltonian Laceability in the Brick Product $\mathrm{C}(2 \mathrm{n}+1,1, \mathrm{r})$ Advances in Applied Mathematical Biosciences.ISSN22489983,Volume5,Number1(2014), pp.13-32.

[6] G.Manjunath, R.Murali and S.K.Rajendra, Laceability in the Modified Brick Product of Odd Cycles, International Journal of Graph Theory, Accepted.

[7] G.Manjunath and R.Murali, Hamiltonian-t*-Laceability, International Organization of Scientific Research (IOSR), ISSN: 2278-3008, p-ISSN: 2319-7676. Volume 10, Issue 3 Ver.III (May -Jun. 2014), PP 55-63. 